\section{Filtering Membranes}

Permselective Membranes. Edited by C. E. Rodgers. (Selected papers presented at the American Chemical Society Symposium, New York, September 1969.) Pp. xi+206. (Marcel Dekker: New York, September 1971.) $\$ 14.50$. (First published in Journal of Macromolecular Science, Vol. 5B, No. 1, 1971.)

I READ this collection of diverse contributions to various aspects of membrane transport mechanisms hoping that there might be found within these pages well-defined achievements or clear statements of problems seeking solution.

I found neither. The publication contains random contributions on mechanistic rate studies of gas transfer in acrylates, block copolymers, silicone rubbers and irradiated fluorocarbon films. It also contains yet more fundamental studies of solute and water transport in hyper-filtration membranes, and anyone however vaguely acquainted with the field must know by now that $P=D x S$.

The editor states in the preface of this volume that "An ultimate aim of research in this field is to establish mechanisms and laws relating solubility and transport in multi-component systems with the molecular properties and characteristics of the components". True and worthy, no doubt, but for the permselective membrane field to achieve true credibility in areas other than the artificial kidney (scantily mentioned), another and perhaps more pressing and immediate aim of research into membrane permeability would be to tackle immediate problems where permselective membranes could make immediate contributions.

In the desalination field, cellulose acetate lacks certain mechanical properties to withstand creep when solutions are pumped over its surface at fluid velocities which determine possible economic operation of desalting plant. It therefore lacks credibility. But cellulose acetate membranes could perhaps replace sand and gravel filters for sewage and organic component removal if open-pore membranes could produce fluxes approaching the 120 (UK) gallons square foot per hour given by gravel filters. An immediate application for a permselective membrane? We need to know.

In the medical field, is it possible fully to oxygenate 51 . of blood per minute, simultaneously exchanging carbon dioxide to acceptable partial pressures with a permselective silicone membrane in view of the fact that direct process equipment produces extremely serious blood damage? We need to know. These questions remain unanswered by this book, in spite of the fundamental knowledge which has been gathered in the past decade on membrane systems for separation processes.

\section{W. M. MUIR}

\section{Free Radicals in vivo}

Free Radical Mechanisms in Tissue Injury. By T. F. Slater. Pp. 283. (Pion: London, 1972.) £4.80. Students' edition, $£ 3$.

IN these days of ever increasing specialization in science any attempt to bridge the gaps between traditional disciplines is welcome. An example of bringing together some of the interests of physical chemistry and physiology is provided by this monograph. Although this is the expressed aim of the author, he has not used the most effective way to achieve his purpose. As he himself points out, it is difficult to gain the confidence of any specialist by discussing his subject incompletely. It is obviously a near impossible task to describe in some eighty pages free radical re. actions including techniques. Inevitably the author's selection is unlikely to appeal to everybody. Inevitably and perhaps wrongly, the reader with some knowledge in free radical work suspects that the treatment of the physiological points may suffer from similar defects. An even slightly discouraged reader is unlikely to become interested and stimulated enough to want to go into the new field. In my view the author would have been more successful if he had provided two shorter monographs in which the ration of one discipline was confined to less than $10 \%$ of that of the other. A ten or twenty page introduction to the specialty of the reader with reference to standard textbooks would be less likely to produce an unwanted reaction.

In the introduction of two to three pages the author provides a definition of free radicals and, surprisingly, a description of membranes and their importance to living tissues. Their relevance to this monograph is justified as follows: since membranes often contain unsaturated lipids and are surrounded by oxygen rich, metal containing fiuids they are susceptible to peroxidative attacks which involve free radical reactions. After these short remarks the reader is given a description of free radicals, their production, chemical reactions, methods of detection, free radical scavengers, their occurrence in biological materials and some of their deleterious reactions with biologically important materials. This part, about a third of the monograph, is lucid and cohesive. The author then builds up in a few pages to his real interest, which is the action of carbon tetrachloride on the liver, leading to fatty degeneration and necrosis. Hepatotoxic effects of alcohol follow with a predominantly physiological and biochemical discussion giving very little information on free radical involvement. The liver and its reactions take up more than a third of the book. Free radical damage to biological membranes is discussed in some 20 pages which no doubt should appeal to free radical chemists, providing a concise and interesting introduction to this field. Free radical involvement in chemical carcinogenesis and radiation-induced tissue damage get only some thirty-five pages and are correspondingly sketchy although this subject fits the title of the book very well. The book ends with a few pages on iron and copper toxicity which unfortunately are only loosely linked to free radical mechanisms.

The style of writing is precise and the literature citations are adequate for further information in unfamiliar fields. The book was printed by a photolitho process but is well produced with clear illustrations and a good subject index. For the non-initiated but interested reader it would have helped to get a more obviously cohesive choice of examples from the biological field with perhaps more indications of possible physico-chemical approaches to the problems involved. With some courage, however, the author has produced a useful and readable selection of chemical and physiological facts. Those scientists already working in this interdisciplinary area will appreciate it greatly. How many new converts this monograph is going to make only the future will tell. But even if only a handful of good physical chemists are encouraged to enter the physiological field they should be in a position to make a contribution. Let us prevent science from drifting apart and get some help from books like this to follow the literature in areas outside our own specialties. M. EBERT

\section{Archaeology in Context}

Environment and Archaeology: $A n$ Ecological Approach to Pre-history. By Karl W. Butzer. Second edition. Pp. xxvi+703. (Methuen: London, May 1972.) $£ 8$.

WHEN Professor Butzer originally wrote this book he set himself a tremendous task: a review of the wide range of techniques used in studying the Ice Age and a series of selected examples of geographical reconstructions of certain areas and certain phases in the Pleisto- 